\title{
La política lechera en Chile
}

DOI: $10.32870 /$ mycp.v5i15.158

Ramón Robledo Padilla*

I

\section{ntroducción}

La industria de la leche en Chile ha reportado avances significativos en el último lustro. Esto se muestra en el incremento de la producción y en el comportamiento de la balanza comercial de lácteos, que pasó de ser marcadamente deficitaria para luego alcanzar un superávit importante en el 2001.

En este artículo se analizan las causas de dicho cambio, sucedido en el contexto de un mercado internacional de lácteos fuertemente distorsionado debido a los altos subsidios que se aplican en países desarrollados. El caso de Chile, por sus particularidades, no podría generalizarse con el de otros países (por ejemplo, México, que es uno de los principales importadores de productos lácteos en el mundo). En este sentido cabe cuestionarnos ¿cómo le hizo Chile para desarrollar este sector en un contexto global adverso en el que el manejo de los subsidios juega un papel importante en la problemática del sector?

\section{Antecedentes}

Antes de la década de los años setenta Chile había adoptado una política de desarrollo económico hacia dentro tratando con ello de desarrollar la industria interna para poder acceder al mercado de los precios altos, es decir, cambiar su estructura productiva de bienes primarios vendidos en el comercio internacional a precios bajos, por una de productos con valor

* Investigador del Departamento de Estudios del Pacífico de la Universidad de Guadalajara. agregado donde los precios son más estables y redituables con el transcurso del tiempo. La estrategia se basaba en dos puntos: el primero consistía en desarrollar la industria a costa del sector primario, que ofrecía al secundario alimentos y materias primas a bajos precios; el segundo consistía en proteger al sector industrial de la competencia externa mediante la aplicación de altos niveles arancelarios. Este esquema se modificó en los años setenta y a partir de entonces el sector externo iba a jugar un papel importante dentro del nuevo modelo de desarrollo; la nueva forma que adoptó el desarrollo económico de Chile consideraba dos elementos principales: primero, producir aquellos bienes en los que el país pudiera competir y, segundo, la ampliación del mercado. El segundo elemento tenía que ver con la preocupación del reducido tamaño del mercado interno para los productos chilenos, es por eso que el mercado externo ocupó un lugar importante en la estrategia de desarrollo nacional ${ }^{1}$.

\section{Importancia del sector primario}

Dentro de este marco general de la estrategia de desarrollo de Chile se ubica su sector primario de gran importancia en su economía; al igual que en muchos otros países subdesarrollados, este sector se considera prioritario por el número de personas empleadas, su participación en el total de exportaciones del país y su contribución al PIB total, que generalmente es muy superior, en términos relativos, al observado en economías desarrolladas. 
Pese a los problemas estructurales, donde los sectores quedan expuestos al libre mercado y la competencia exterior es cada vez más fuerte, el sector silvoagropecuario de Chile creció a una tasa de 3.3 por ciento anual durante la última década. En la actualidad es fuente de empleo de 14 por ciento de la población ocupada $(777,000$ empleos) y tiene una participación relativa en el PIB total, que pasó de 8 por ciento en 1990 a 5.9 por ciento en 2000 ; esta reducción se debe al crecimiento económico del país que creció en la última década a una tasa de 6.6 por ciento anual. En términos absolutos, el sector primario creció 38 por ciento en el mismo período, al pasar de 360 mil millones de pesos en 1990 a 499 mil millones de pesos en 2000. Otra razón de la importancia del sector primario en la economía de Chile es su aportación al comercio exterior, actualmente contribuye con cerca de 30 por ciento del valor total de las exportaciones totales; en el año 2000 las exportaciones del sector fueron 4,986 millones de dólares con un saldo favorable en la balanza de 3,785 millones de dólares ${ }^{2}$.

\section{Sector de la leche en Chile}

Dado lo anterior, se puede decir que el sector primario es muy importante para Chile por su participación relativa en el total de la economía. En este orden de ideas, uno de los subsectores principales, dentro del sector primario, lo constituye el sector de la leche; esta actividad tiene mayor relevancia, principalmente para la región décima del país donde se produce más de 70 por ciento del total nacional. Lo que hace atractivo a este sector, se debe a que a escala internacional es competitivo y se puede consolidar en el futuro como fuente importante de divisas como se mostró en 2001, año en que la balanza comercial del sector tuvo un crecimiento importante con saldo positivo de $\mathbf{9 . 5}$ millones de dólares.

El sector lechero en Chile forma parte del subsector pecuario; contribuye con el 0.7 del PIB nacional ${ }^{3}$, se compone de 22,000 productores, alrededor de 600,000 vacas lecheras y en la última década experimentó un fuerte proceso de modernización productiva ${ }^{4}$ que se vio reflejado en las cifras de producción, de 1,380 millones de litros en 1990 a 2,200 en 2001. Sin embargo, a pesar de que el sector es considerado muy productivo por los precios pagados al productor (en 1998, según una fuente de la FAO, en Chile se pagaba entre 21 y 25 centavos de dólar por litro, en los Estados Unidos entre 31 y 35 centavos, y en Japón entre 55 y 60$)^{5}$, el sector enfrenta una serie de problemas, comenzando con los subsidios que se aplican en países desarrollados como los de la Unión Europea y Estados Unidos que finalmente inciden en menores precios internacionales $\mathrm{y}$, en segundo lugar, por los escasos apoyos del gobierno chileno, que se vinculan con la estrategia de apertura hacia el sector externo, donde el mercado de lácteos se encuentra distorsionado

Cuadro 1

\begin{tabular}{ccccccc}
\hline \multicolumn{5}{c}{ Producto Interno Bruto (PIB) y fuerza de trabajo ocupada en la agricultura1990-2000 } \\
\hline Años & \multicolumn{2}{c}{ miles de millones de pesos de 1986 } & \multicolumn{4}{c}{ miles de personas } \\
& PIB nacional & $\begin{array}{c}\text { PIB } \\
\text { S. primario }\end{array}$ & $\begin{array}{c}\text { Participación\% } \\
\text { s. primario/nacional }\end{array}$ & Agricultura & País & Agricultura/País \\
\hline 1990 & 4,484 & 360 & 8.0 & 858.0 & $4,459.6$ & 19.2 \\
1991 & 4,841 & 364 & 7.5 & 866.2 & $4,540.4$ & 19.1 \\
1992 & 5,435 & 405 & 7.5 & 860.1 & $4,773.3$ & 18.0 \\
1993 & 5,815 & 416 & 7.2 & 845.8 & $4,985.7$ & 17.0 \\
1994 & 6,147 & 441 & 7.2 & 808.9 & $4,988.3$ & 16.2 \\
1995 & 6,800 & 464 & 6.8 & 789.2 & $5,025.8$ & 15.7 \\
1996 & 7,305 & 470 & 6.4 & 816.4 & $5,298.7$ & 15.4 \\
1997 & 7,845 & 452 & 5.8 & 775.9 & $5,380.2$ & 14.4 \\
1998 & 8,153 & 481 & 5.9 & 784.4 & $5,432.4$ & 14.4 \\
1999 & 8,059 & 475 & 5.9 & 780.1 & $5,404.5$ & 14.4 \\
2000 & 8,493 & 499 & 5.9 & 777.0 & $5,381.5$ & 14.4 \\
\hline
\end{tabular}

http://www.odepa.gob.cl/servicios-informacion/publica/Compendio-2000.pdf pp. 113 y 120 (05/05/2002) 
en más de 30 por ciento ${ }^{6}$, lo que quiere decir que, sin subsidios, los precios internacionales de la leche serían $30 \%$ más altos de lo que son en la actualidad. Ante esto, el sector lechero debe intensificar su proceso de modernización, incrementar los estándares de calidad y la eficiencia productiva, para lo cual requiere bajar los costos de producción y utilizar a la pradera como fuente principal de alimentación en las regiones del sur. Esto es posible dadas las condiciones naturales que posee, características de manejo, fertilización y especies utilizadas en las pasturas que son muy similares a las de Nueva Zelanda (país muy competitivo como productor de leche en el mercado internacional). Asimismo, se precisa mejorar la productividad en el sector industrial, al mismo tiempo que se permita desarrollar una estrategia para exportar los excedentes eventuales y, finalmente, plantear una estrategia para enfrentar a largo plazo las distorsiones del mercado mundial de lácteos que originan los Estados Unidos y la Unión Europea.

\section{Cuadro 2}

\begin{tabular}{cc}
\hline \multicolumn{2}{c}{$\begin{array}{c}\text { Producción de leche, } 1990-2000 \\
\text { millones de litros }\end{array}$} \\
\hline Años & Producción de leche \\
\hline 1990 & 1,380 \\
1991 & 1,450 \\
1992 & 1,540 \\
1993 & 1,650 \\
1994 & 1,750 \\
1995 & 1,850 \\
1996 & 1,924 \\
1997 & 2,050 \\
1998 & 2,080 \\
1999 & 2,050 \\
2000 & 1,990 \\
2001 & 2,200 \\
\hline http://www.odepa.gob.cl/servicios \\
-información/pública/Compendio-2000.pdf \\
(05/05/2002)
\end{tabular}

Un problema adicional, que está muy relacionado con la distorsión de los precios de la leche en el mercado internacional, se debe a la gran concentración láctea en el mercado interno. Por ejemplo, en Chile, cuatro de las empresas más grandes dominan la recepción de leche con
80 por ciento de la producción nacional. Un estudio de Consumers International sobre la industria lechera en Chile reveló que, debido a lo anterior, tanto productores como consumidores se han visto afectados por esta situación y por la competencia desleal que predomina en los mercados internacionales. La baja en los precios internacionales se debe, como habíamos dicho, a los subsidios; quienes se han beneficiado de esto son unas pocas empresas industriales que se reparten el mercado, controlando los precios de compra y venta de la leche. La empresa SOPROLE es una de las que ostenta una posición dominante, ya que controla 28 por ciento de la recepción de leche a escala nacional, asimismo, es el mayor importador del sector, lo que le permite aprovechar los bajos precios en el mercado internacional y presiona la baja en los precios en el mercado interno con perjuicio del productor. A esta empresa, que es controlada por la New Zealand Dairy Board con 51 por ciento de la propiedad de las acciones, se le ha acusado de traer quesos y leche excedentaria en polvo desde Nueva Zelanda, y de ser la responsable directa de la caída en los precios al productor en los últimos años. Los productores aseguran que las otras plantas la siguen, puesto que por su tamaño esta empresa también maneja los precios a nivel del consumidor, que se han mantenido o aumentado hasta en 12 por ciento ${ }^{7}$, no obstante la caída en el precio de la materia prima.

El sur de Chile es la principal región lechera del país; en la región diez se concentra el mayor número de vacas lecheras, poco más de 60 por ciento del total. Asimismo, es la región

Cuadro 3

\begin{tabular}{lcc}
\hline \multicolumn{3}{c}{ Estructura de la industria lechera en Chile } \\
\hline Nombre de & Recepción de leche & 1999 \\
empresa & miles de litros & $\%$ \\
\hline Soprole & 411,787 & 28 \\
Nestlé & 326,792 & 22 \\
Loncoleche & 221,281 & 15 \\
Colun & 212,488 & 15 \\
Parmalat & 92,322 & 6 \\
Otros & 200,765 & 14 \\
& & \\
Todo el país & $1,465,436$ & 100 \\
\hline
\end{tabular}

http://www.fao.org/ag/AGA/AGAL/papers/policypaper04.pdf p. 46 $(05 / 05 / 2002)$ 
donde se produce más de 60 por ciento de la producción total; aproximadamente 20 por ciento adicional se produce en las regiones octava y novena, lo cual indica que estas regiones concentran 80 por ciento de la producción

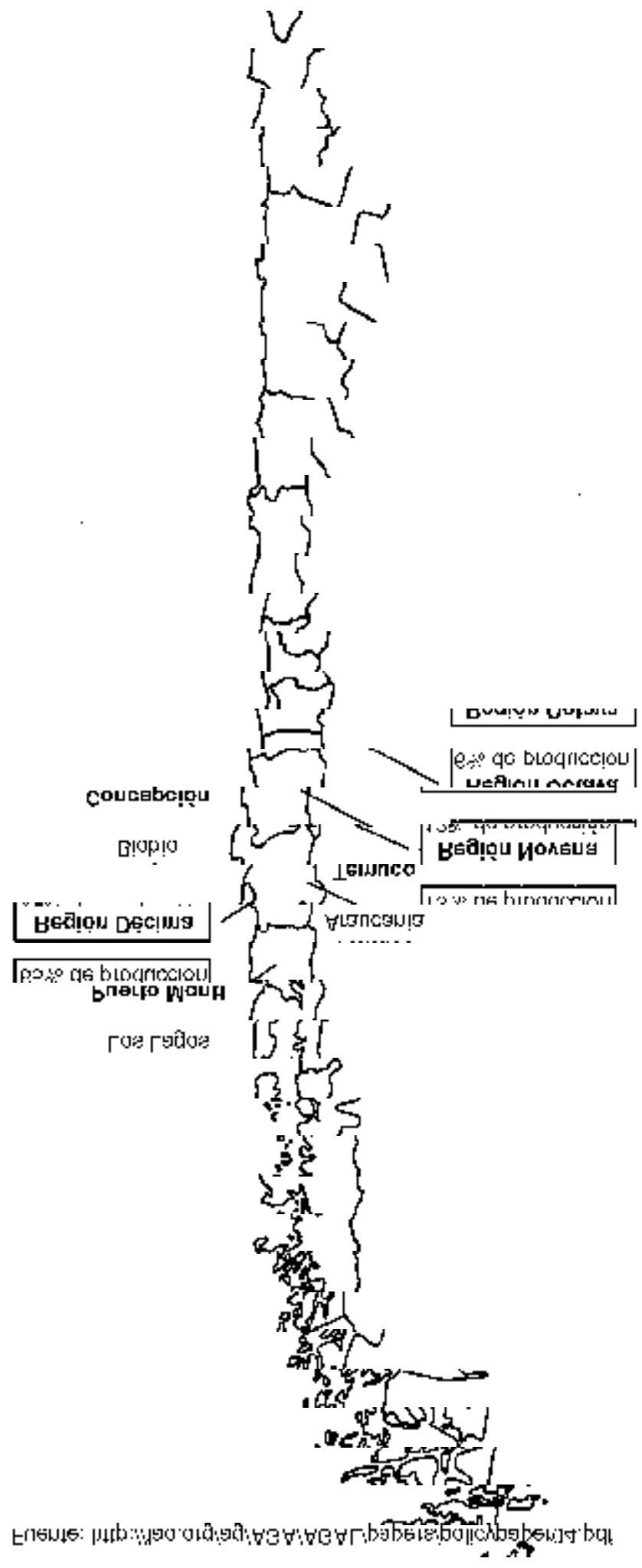

nacional. En las zonas más secas del norte, con posibilidades de riego, son más rentables las actividades agrícolas intensivas. En el sur, con mayor humedad y menores temperaturas, resulta competitiva la producción de leche sobre la base de las pasturas ${ }^{8}$.

Finalmente, en lo que se refiere al comercio exterior, el saldo de la balanza comercial de lácteos había sido deficitaria hasta antes del 2001. En 1996 alcanzó un déficit de 49.4 millones de dólares, pero en 1999 se tuvo un saldo positivo de 60 mil dólares. En el 2001 las exportaciones tuvieron un repunte importante con lo cual se alcanzó nuevamente un saldo positivo en el comercio de lácteos de 9.5 millones de dólares. Este importante incremento en las exportaciones se debió básicamente a un incremento en la producción de leche motivado por una situación climática favorable y a una recuperación de los precios pagados al productor de leche, especialmente entre enero y septiembre de 2001 donde los precios aumentaron 13.7 por ciento $^{9}$, después de una década en la que los precios habían estado disminuyendo.

No obstante que los chilenos tienen en mente incrementar sus exportaciones en los próximos años con una meta de 100 millones de dólares anuales, la dependencia en los cambios climáticos y la inestabilidad en precios pagados al productor constituyen un gran problema para el logro de dichas expectativas; sin embargo, proyectos como la creación del Centro Nacional de Capacitación y Entrenamiento en Reproducción y Manejo Animal CENEREMA que comenzó en 1999, y que al momento lleva un monto de inversión de 700 millones de dólares con el objeto de mejorar la productividad de los pequeños productores lecheros de la décima región ${ }^{10}$, constituye un importante avance para mejorar la organización y productividad del sector. El proyecto tiene como objetivo principal aumentar la productividad ganadera de las pequeñas lecherías de esta región con las fases siguientes: capacitación de especialistas en reproducción, alimentación y manejo animal; difusión de la tecnología apropiada entre los productores y mejoramiento genético del ganado bovino ${ }^{11}$. 
Cuadro 4

\begin{tabular}{lrrrrrrr}
\hline \multicolumn{7}{c}{ Comercio exterior de productos lácteos en Chile } \\
Miles de dólares \\
\hline Exportaciones & 1995 & 1996 & 1997 & 1998 & 1999 & 2000 & 2001 \\
\hline Importaciones & 26,439 & 26,231 & 28,432 & 27,696 & 31,257 & 27,000 & 44,500 \\
Saldo & 55,109 & 75,631 & 41,946 & 45,683 & 31,197 & nd & 35,000 \\
\hline http://www.fao.org/ag/AGA/AGAL/papers/policypaper04.pdf p.48(05/05/2002) & $-28,670$ & $-49,400$ & $-13,514$ & $-17,987$ & 60 & & 9,500 \\
\hline
\end{tabular}

En Chile no existen derechos de exportación, subsidios a la producción, ni programas que promuevan las exportaciones; sin embargo, existen "reintegros simplificados" para apoyar la exportación, lo que permite una devolución de hasta 10 por ciento del valor de las exportaciones. Los acuerdos con la OMC ponen fin a este instrumento al finalizar el 2003. Tampoco existe una protección arancelaria acorde a las distorsiones presentadas en el mercado internacional. En 1999 el arancel general fue de 10 por ciento, mientras que en 2001 fue de 8 por ciento para todos los productos importados. En el caso de la leche en polvo y la leche UHT hay una sobretasa de 12 por ciento. En general la protección arancelaria y los reintegros son relativamente bajos frente a las posibilidades que se presentan en la OMC (25 por ciento arancel máximo, 31.5 por ciento en casos excepcionales, entre ellos se encuentran los lácteos $)^{12}$.

\section{Fuentes}

1. http://www.odepa.gob.cl/servicios-informacion/publica/ Inser-Inter-Agricultura.pdf p. 4 y 5.

2. http://www.odepa.gob.cl/servicios-informacion/publica/ Compendio-2000.pdf p. $116(05 / 05 / 2002)$

3. http://www.diariollanquihue.cl/site/edic/ 20020405061341/pags/20020405080754.html

4. http://www.odepa.gob.cl/servicios-informacion/publica/ Agricultura-2010.pdf p. 26

5. http://www.agronegocios.cl/parte1.200

6. Ibidem

7. http://www.consumersinternational.org/campaigns/ trade-2-s.pdf p. 4

8. http://www.fao.org/ag/AGA/AGAL/papers/ policypaper04.pdf p. 41

9. http://odepa.gob.cl (sección noticias)

10. Este proyecto se firmó en el marco del convenio suscrito por el Ministerio de Agricultura y la Agencia de Cooperación Internacional de Japón JICA que opera a través del CENEREMA.

11. Op. cit. http://odepa.gob.cl

12.Op. cit. http://www.fao.org/ag/AGA/AGAL/papers/ policypaper04.pdf p. 49 T?:- 